Revista de Ciencias Sociales - Número 66 (2015) - Páginas 221-223

Manson Terrazas, Manuel: Introducción al Derecho. Ed. Olejnik. Santiago...

\title{
MANSON TERRAZAS, MANUEL: Introducción al Derecho. Ed. Olejnik. Santiago, Chile. 2012. 198 Págs.
}

Durante la primera quincena del mes de marzo de 2012, tuve el gran placer de recibir la primera edición de imprenta del texto "Introducción al Derecho", de manos de su propio autor, el Dr. Manuel Manson Terrazas ${ }^{1}$, quien con esta obra mantiene viva con sus lectores una relación intelectual iniciada en 1962, con la publicación por la Editorial Universitaria de su tesis "Introducción a una semántica de los sistemas normativos". Pienso, como Griesebach, que "la mayoría de los libros caen en el olvido porque una impresión duradera la dejan solo aquellos en los que su autor se halla encarnado por completo"2.

1. Efectivamente, conforme a la lectura del texto, queda claro que se trata de una introducción al estudio del Derecho, que prestará su mayor utilidad en la medida en que sea leído por quienes desarrollen su labor como profesores o investigadores jóvenes, sin perjuicio de que sea utilizado como un material indispensable en las lecturas de los estudiantes de los primeros años de las carreras de Derecho. Así se advierte ya en la estructuración de los temas y capítulos, desde el prefacio

1. Doctor en Derecho por la Universidad Complutense de Madrid. Miembro de la Sociedad Chilena de Filosofía Jurídica y Social, y Fundador de la Sociedad Chilena de Lógica, Metodología y Filosofía de las Ciencias.

2. GRIESEBACH, Eduard: Schopenhauer. Gechichte seines Lebens [Historia de la vida de Schopenhauer]. Ernst Hoffman \& Co., Berlín, 1897. Pág. 267. Citado por MORENO CLAROS, Luis: Schopenhauer. Vida del filósofo pesimista. (2005). Ed. Algaba. Madrid. p. 14.

Revista de Ciencias Sociales - Número 66 (2015) - Universidad de Valparáíso - ISSN 0716-7725-Valparáiso, Chile 
— con la mención inicial de las palabras de santo Tomás sobre los usos del término 'derecho'-, pasando por capítulos sobre el lenguaje directivo, la norma fundamental, la interpretación y el razonamiento jurídico, los valores y los fines del Derecho, y los principios jurídicos fundamentales, hasta llegar al capítulo final, sobre la lógica, la filosofía y el hombre de derecho, y al apéndice sobre el aprendizaje del Derecho (pp. 193-196).

Resultan enriquecedoras las referencias a autores que pocas veces son tocados en textos que hacen una reflexión sobre el Derecho desde la óptica de la Filosofía del Derecho: Roscoe Pound, Zagrebelsky, Lachmayer, Toulmin, Ziembinski y Bochenski, por ejemplo. Ellas reflejan la intención de comunicar y transversalizar una manera de pensar el Derecho y la formación de los futuros juristas, de los no tan nuevos, y también de quienes no lo son ni pretenden serlo. En tal orden, una cita de "El método funcional en el derecho", de Felix S. Cohen, sirve para expresar una convicción del propio autor: "El derecho no es una masa de decisiones desconectadas ni un producto de los cólicos estomacales de los jueces. (...). Una teoría verdaderamente realista de las decisiones judiciales tiene que concebir cada decisión como algo más que la expresión de la personalidad individual" (p. 195).

El libro está dedicado a la memoria de Georges Kalinowski, quien afirmara, como recuerda el autor: "No se puede ser filósofo del derecho, si no se es, lisa y llanamente, filósofo" (p. 7).

2. Llama a la reflexión la lógica elección de los temas, los cuales, para quien posea algún grado de formación jurídica, resultarán casi naturalmente conectados. El capítulo 4 ("Kelsen y la norma fundamental”, pp. 35-58), por ejemplo, aparece complementado con el capítulo 12 ("Hans Kelsen y la lógica del derecho", pp. 115-124), evidenciando ambos respeto intelectual por este autor y una valoración crítica de su obra, siendo actualmente pocos quienes estudian tan profundamente a Kelsen, sabiendo distinguir sus aportes de sus errores.

El intermedio argumentativo dado por el capítulo 9 ("Racionalidad jurídica y lógica formal", pp. 95-100) me ha parecido de una claridad y precisión notables. Notable también es su explicación sobre el argumento a fortiori (pp. 84 y 89). Igualmente destacables son los párrafos 20 y 21 del capítulo 8 , relativos a los desafíos de la educación jurídica y de la administración de justicia. 
3. El texto debería ser un llamado al estudio y a la reflexión. Así el lector atento podrá coincidir con esta afirmación del autor: "No se conoce bien el derecho si se olvidan las razones de su establecimiento o se prescinde de las modalidades de su aplicación" (p. 193).

El libro es digno del mérito y del trabajo incansable del autor. A él mis palabras de agradecimiento por una enseñanza justa y un impulso intelectual honesto.

\author{
Alejandro Robledo Rodríguez \\ Doctorando en Filosofía \\ Universidad de Los Andes (Chile)
}

